\title{
La nueva economía popular: ¿Una utopía realizable?
}

\section{Introducción}

A la Nueva Economía Popular (NEP) no la concebimos como un modelo alternativo al modelo neoliberal que impulsa el gobierno, sino como estrategia alternativa de y para los sectores populares no vinculados por relaciones salariales al Sector Capitalista de la Economía o al aparato estatal.

Tal estrategia posibilitaría amortiguar los efectos sobre los sectores populares del modelo neoliberal en su fase actual, definida por nosotros como re-acumulación primaria del capital, ${ }^{1}$ y a su vez, con la experiencia ganada, con las conquistas logradas en el foro de concertación popular con la captación de recursos durante el proceso de reconstrucción, podría ampliarse y desarrollarse en el mediano plazo.

De ser ésto así, la NEP podría llegar a coexistir con el sector capitalista de la economía, pero ya no como un simple apéndice del mismo, ni en función de los intereses del capital, sino con su propia lógica de reproducción, lo cual conduciría o haría posible, al menos que habiendo logrado la NEP importancia económica, política y social, se definiera una nueva forma de organización social, auténticamente democrática, ya que a la democracia económica y social.

Bien, tal es la importancia que reviste la NEP, lo cual justifica una investigación teórico-empírica que nos permita establecer: a) Cuál es la realidad presente de la Economía Popular?; b) Cuáles serían las premisas básicas de la Nueva Economía Popular?; c) Cuáles son los límites y las potencialidades de la NEP?; d) Estudio teóricoempírico de algunas experiencias actuales de gérmenes de la NEP; y finalmente,

e) Presentar lineamientos fundamentales acerca de la integración y funcionamiento de la NEP. 


\section{La economía popular}

A fin de evitar cualquier equívoco es preciso explicitar que por economía popular entendemos todas aquellas actividades económicas no capitalistas, ni estatales presentes en la órbita de la producción material e inmaterial, así como en la circulación, ya sea que se ubiquen espacialmente en el área urbana o rural. Ejemplos de estas actividades serían la producción campesina o el denominado sector informal urbano.

Tal economía popular ha sido una constante en nuestra sociedad, aunque en los últimos años ha cobrado una mayor importancia en las actividades urbanas debido al desempleo y a los espacios dejados por el capital, entre otras razones; sin embargo ha sido una economía funcional al capital en tanto ha estado subsumida indirectamente al mismo, en consecuencia ha posibilitado la valorización extraordinaria del capital en tanto la relación entre el capital y la economía popular se ha caracterizado por la expoliación, esto es, por una transferencia de valor desde la economía popular hacia el capital genérico, amén de otras formas o mecanismos menos evidentes. $^{2}$

Si bien lo anterior es un problema radical que deberá enfrentar la nueva economía popular, existen un cúmulo de problemas adicionales que es preciso explicitar a fin de tener claros los límites y posibilidades de lo que estamos proponiendo como una estrategia alternativa o bien, qué problemática es preciso resolver a fin de que la nueva economía popular se constituya en auténtica estrategia alternativa.

Es casi un lugar común el hecho de que la economía popular se enfrenta a problemas tales como: carencia de asistencia técnica; bajos niveles tecnológicos; falta de maquinaria y equipo; bajos niveles de productividad; el no acceso al crédito de la banca; ausencia de controles administrativos, e incluso, contables, fruto de la no capacitación formal y/o técnica; la incapacidad de almacenamiento de la producción y la comercialización directa de la misma y en pequeñas cantidades, problemas derivados de la lógica capitalista con que opera la banca y el poco interés de parte del Estado de fomentar realmente a la economía popular, así como de su práctica individualista y atomizada, de lo cual se deriva su insuficiente y generalmente nula organización, lo cual la hace más débil y vulnerable.

Adicionalmente la economía popular carece prácticamente de una integración en si misma, sus relaciones han sido de carácter bilateral con el sector capitalista de la economía, al menos, en cuanto operan como compradores $y$, en 
menor proporción, cuando operan como vendedores, ello ha posibilitado un intercambio desigual que sólo ha favorecido al sector capitalista.

No menos despreciable es la lógica con que generalmente opera la economía popular, la cual podría simplificarse diciendo que es una lógica de sobrevivencia impuesta por la carencia de un excedente o bien, por la carencia de una lógica reproductiva en escala ampliada. Se prefiere el consumo presente a la reinversión del excedente que podría posibilitar una mayor satisfacción de necesidades a futuro. No es de extrañar tal comportamiento ante el cúmulo de necesidades insatisfechas y ante la presión consumista que genera la economía capitalista, e incluso, debido a la ausencia de mecanismos contables que les permitan diferenciar el ingreso bruto del ingreso neto.

Pues bien, tal economía popular atomizada, desintegrada, expoliada, desorganizada, carente de financiamiento, de capacitación formal y técnica, simplemente reproduciéndose y multiplicándose pero sin mejorar su productividad, ni sus ingresos, profundamente individualista no puede constituir una estrategia alternativa para las mayorías populares no asalariadas, ni es nuestra intención proponerla como tal, nuestra propuesta hace referencia a una nueva economía popular.

\section{La nueva economía popular}

\section{Introducción}

Debo confesar que desde hace algunos años conocí algunos "proyectos" que llevaban a cabo en zonas marginales algunos buenos amigos estudiantiles jesuitas, pero que entonces los vi tan sólo como esfuerzos tendientes a mitigar la extrema miseria de algunos sectores de las mayorías populares, en tal sentido no las cuestioné pero tampoco les concedí mayor importancia, por mi mente pasaron aqueIlas viejas experiencias fallidas de Robert Owen y Saint Simon. Algo similar me pareció la experiencia de Colomoncagua, "son proyectos en invernadero", me dije: "al entrar en contacto con la realidad capitalista serán asimilados y todo quedará como un maravilloso sueño que no pudo ser". Confieso, honestamente, lo anterior porque se que no pocos reaccionarán de la misma manera ante el planteamiento que ahora nosotros haremos en torno a la nueva economía popular, sin embargo, como estoy convencido de que bien puede llegar a convertirse en una estrategia alternativa es que ahora me ocupo de esta realidad nueva que ha sido generándose al margen de los manuales y de las teorías existentes. Deseo también aclarar que no se trata de El otro sendero 
de Hernando de Soto, ${ }^{3}$ precisamente todos los trabajos por mí publicados sobre la subsunción indirecta del trabajo en el capital, han buscado ser una interpretación alternativa a las de la "corriente informal" de la economía, en consecuencia no podría venir ahora a plantear como una estrategia alternativa aquello que he cuestionado en el pasado. Por tal razón es que hablamos de una Nueva Economía Popular.

Adicionalmente deseo expresar que la nueva economía popular como la entiendo y desarrollaré infra aún no existe como tal, aunque sí se presenten ya algunos elementos constitutivos de la misma, en tal sentido es una utopía en el buen sentido del término, como aquello aún no realizado, como un proyecto de las mayorías populares y para las mayorías populares no vinculadas con el capital a través de relaciones salariales.

No deseo concluir sin señalar que para quienes no le concedemos al capitalismo capacidad real de resolver los problemas socio-económicos de las mayorías, mucho menos al modelo de capitalismo hacia el cual nos encaminamos, la utopía se convierte en una necesidad y con mayor razón, cuando se ha desmoronado aquel proyecto de sociedad, denominado socialismo histórico o real que si bien no logró ser lo que se proponía, si había logrado disminuir significativamente los niveles de miseria económica y social.
Para concluir esta introducción deseo agregar, que para quienes compartimos el ideal de la UCA, esto es, la opción preferente por las mayorías populares, se nos impone como imperiosa necesidad el buscar alternativas reales, efectivas y viables, para esas mayorías populares y ello, creemos haberlo encontrado en la nueva economía popular.

\subsection{Premisas de la nueva economía popular}

En el modo de producción capitalista la producción como totalidad determinada la distribución, el cambio y el consumo; aunque a su vez la producción unilateralmente considerada puede ser a su vez determinada por la distribución, el cambio y el consumo. La producción en tanto que reproducción es obvio que reproduce la forma de distribución, el cambio y el consumo. Es claro que si la producción se efectúa bajo relaciones salariales capitalistas, la forma de tener acceso a la distribución es a través del salario, así quien no tiene oportunidad de vender su fuerza de trabajo no participa en la distribución y no cuenta en el mercado.

Pero bien, tal recordatorio cumple tan solo un propósito, cual es presentar la primera premisa de la NEP: la producción en la NEP debe de ser de carácter cooperativo, de tal manera que la distribución se le corresponda. ¿Qué queremos decir con que se le corresponda? Pues es 
muy simple, si la producción, por ejemplo, es carácter individual los frutos de la misma serán solamente para el individuo. En cambio, si la producción es cooperativa los resultados de la misma corresponderán proporcionalmente a todos aquellos que hayan participado en la misma. El trabajo cooperativo además de significar un ahorro en términos del empleo de los medios de producción (lo correspondiente a capital fijo), posibilita a su vez incrementar la productividad del trabajo, mediante la emulación, la división social del trabajo, etc. Pero además de lo anterior, que no es nada despreciable, la cooperación sí posibilita la equidad en tanto que el excedente disponible beneficia proporcionalmente a todos los socios de las cooperativas. Pero a su vez, todos se beneficiarán del excedente reinvertido ya que con ello se logrará obtener a futuro un excedente mucho mayor. El sacrificio en el consumo presente se justifica en tanto existe la seguridad de lograr a futuro una mayor satisfacción de necesidades.

Debido al importancia que reviste para la NEP la reproducción ampliada, ya sea que la producción se realice de manera cooperativa o individual, deseamos formalizarlo, aunque sea de manera muy esquemática.

$$
\begin{array}{lll}
\text { Sean: VBP } & =\text { Valor bruto de la producción. } \\
\mathrm{Cl} & =\text { Consumo intermedio. } \\
\mathrm{D} & =\text { Depreciación } \\
\mathrm{VAN} & =\text { Valor agregado neto. } \\
\mathrm{W} & = & \text { Salarios (efectivos o imputados) } \\
\mathrm{EN} & = & \text { Excendente neto. } \\
\mathrm{VAN} & = & \mathrm{VBP}-(\mathrm{Cl}+\mathrm{D}) \\
\mathrm{EN} & = & \text { VAN }-\mathrm{W} \\
\mathrm{RI} & = & \text { Parte del excedente que se destina a reinversión. } \\
\mathrm{RD} & = & \text { Parte del excedente que va a otros rubros (impuesto, etc.) } \\
\mathrm{RC} & = & \text { Parte del excedente que se destina a consumo. } \\
\mathrm{RA} & = & \text { Reproducción ampliada } \\
\frac{\mathrm{RI}}{\mathrm{EN}}+\frac{\mathrm{RC}}{\mathrm{EN}}+\frac{\mathrm{RO}}{\mathrm{EN}}=1 \\
\frac{\mathrm{RI}}{\mathrm{EN}}=\mathrm{i}
\end{array}
$$


En consecuencia, tendríamos que cuanto menor sea la proporción que se destine al consumo y a otros rubros, mayor será el nivel de reproducción ampliada, dado un determinado volumen de excedente.

Si a su vez suponemos que la NEP en su primera fase presenta una tendencia a que " $\mathrm{O}$ ", la proporción del excedente que va a otros, sea igual a cero, tendríamos que dado un determinado volumen de excedente la proporción de crecimiento guardaría una relación inversa con la proporción del excedente que se consuma, esto es,

$$
\mathrm{RA}=(1-\mathrm{C}) \mathrm{EN} .
$$

Ello es una obviedad, sin embargo, las cosas obvias son las que a menudo no se tienen en cuenta y la NEP no tendrá ninguna viabilidad si no consigue su reproducción ampliada, si no logra niveles de crecimiento, superiores al menos a la tasa de crecimiento poblacional, la cual en los sectores populares es bastante elevada.

Bien, de lo dicho, se desprende otra premisa fundamental para la NEP, cual es la generación de un excedente neto, pues de no existir éste, sería imposible la reproducción ampliada, lo cual nos conduce a señalar los factores que inciden o que posibilitan la generación de un excedente.

El factor fundamental es, obviamente, la productividad del trabajo, la cual depende de la capacitación técnica del trabajador, de la cooperación y la división técnica del proceso productivo, de la maquinaria y equipo, del aprovisionamiento oportuno de insumos de calidad, etc.

Pero también el excedente puede incrementarse intensificando el ritmo de trabajo y/o prolongado la jornada de trabajo, lo cual tiene sentido cuando los frutos del mayor esfuerzo se revertirán hacia los productores mismos.

Ahora bien, el incremento del excedente en términos físicos, si bien es deseable en la medida que ello posibilita auto-satisfacer las necesidades de los productores, necesita también convertirse en dinero, lo cual nos conduce a la problemática del transporte y la comercialización donde también se requiere de eficiencia. Lo cual, nos va señalando otra premisa de la NEP: la necesidad de su integración sectorial. Esto es más evidente aún, si nos retrotraemos a la fase preproductiva ya que cualquier proceso de trabajo requiere de medios de producción y medios de vida, lo que exige en una sociedad mercantil el contar con dinero que posibilite su adquisición. Esto nos conduce a señalar la necesidad de financiamiento.

En consecuencia, la NEP exige de una articulación sectorial propia, al momento, se nos presentan: financiamiento, producción, transporte y comercialización. 
Pero ocurre adicionalmente que los integrantes de la NEP carecen generalmente de viviendas propias, al igual que de un cúmulo de servicios personales, los cuales son proporcionados a menudo por la economía popular, y que para un mejor funcionamiento de la NEP deberían ser parte integrante de la misma al igual que la construcción de viviendas y los otros sectores antes mencionados.

A fin de presentar una idea ilustrada de lo que entendemos por integración sectorial presentamos en el cuadro $N^{\circ} 1$, lo que podría ser a futuro una Matriz Insumo Producto de la NEP. En ella iniciamos con las compras que efectuaría la NEP al sector capitalista ya sea nacional o mediante importación directa. Luego, siempre por el mismo lado de la oferta se presenta tres grandes sectores: el productivo, el financiero y el comercial, los cuales nos parece que deben de estar integrados dentro de NEP lo más posible; sin embargo es claro que ésta no puede ser una economía autárquica por ello, aparece siempre vinculada a la economía capitalista, aunque la tendencia que debería de buscarse es a una sustitución hasta donde sea posible de las compras al sector capitalista. La razón de ello radica, por una parte, en el intercambio desigual que opera entre ambas economías y, por otra, que toda sustitución implica un incremento en la producción al interior de la NEP, lo cual beneficia a sus integrantes vía generación de empleo y de excedente. La producción la dividimos en diez ramas, las cuales incluyen actividades de producción material e inmaterial. La producción artesanal aparece diferenciada de la manufacturera, debido a que aquella la entendemos como productora de artesanías, las cuales podrían estar orientadas preferentemente a la exportación. En cambio la manufactura la concebimos como una actividad productora de insumos, por ejemplo: abono orgánico, concentrados, fibras de hilo, ladrillos, etc., o bien, productora de bienes de consumo: pan, tortillas, vestido, calzado, etc., o bienes de inversión como arados, carretas, machetes, etc.

La introducción de la rama minas y canteras obedece a que tal actividad puede ser realizada por la NEP, tenemos en mente las minas de oro de baja rentabilidad pero aún explotables para la NEP, las de carbón, las de cuarzo, las de cal, las cuales perfectamente podrían ser explotadas por los sectores populares. Piénsese por ejemplo en el cuarzo el cual no sólo generaría materia prima a la manufactura sino que también a la producción artesanal o en el carbón mineral, el cual podría ser utilizado en la cocción de alimentos asi como en la misma producción manufacturera de artículos de vidrio.

Por el lado de la demanda se nos presentan los mismos tres grandes sectores: producción, financiero 
Demanda total

Demanda final

Var. Existencias

Exportaciones*

Inversión

Duraderos

No duraderos

Alimentos

Consumo privado

Consumo intermedio

는

Comercio

드 Financiero

ํํㄴ Serv. Personales

둔

Z ํㅗㅇ

Almacenamiento

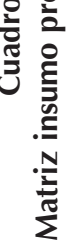

Transporte

Construcción

Vivienda

Manufactura

Artesanal

Minas y canteras

Pecuaria

Agrícola

Producción

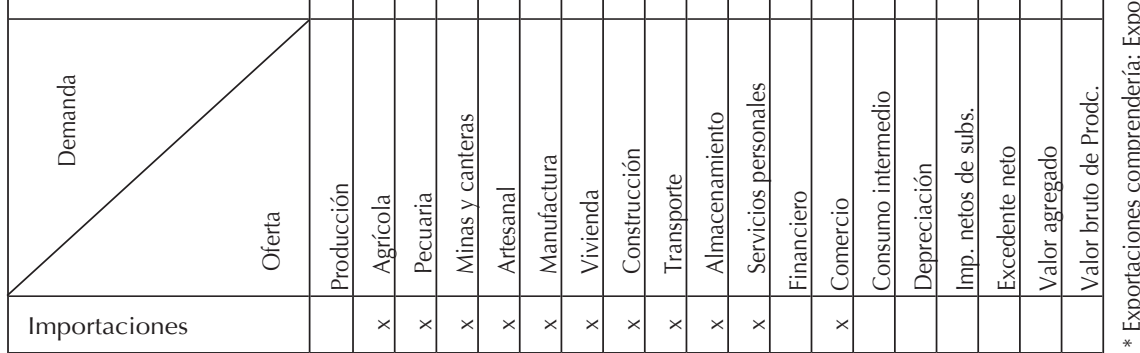


y comercio y las minas diez ramas en que se encuentra dividida la producción; la interrelación sectorial o ramal que presentaría la NEP debería ser mucho más significativa que la generada por el área económica capitalista bajo el nuevo modelo económico orientado preferentemente hacia la exportación de productos del sector agropecuario y con una gran apertura a las importaciones.

En cuanto al consumo privado lo dividimos en tres tipos: productos alimenticios, productos no duraderos y duraderos, la razón de ello radica en la necesidad de destacar la importancia de los alimentos, ya que para las mayorías populares la seguridad alimentaria si es un problema de vida o muerte, de allí que en la NEP la producción y almacenamiento de alimentos deberá ser objeto de una planificación o programación especial. Tal hecho nos está sugiriendo la necesidad de efectuar estudios, investigaciones adicionales que permitan estimar la demanda potencial de los mismos.

También importa destacar dentro del rubro de bienes duraderos: la vivienda, la cual podría ser un factor dinamizador de la NEP, siempre y cuando, al construcción de viviendas tenga un elevado componente de insumos producidos al interior de la misma NEP, lo cual nos induce también a plantear la necesidad de pensar en nuevos materiales de construcción y en nuevas técnicas de producción, todo lo cual debería ser objeto de investigación en el área de Arquitectura de la UCA o de la UES, por ejemplo.

En cuanto a los bienes no duraderos de carácter material su importancia, necesidad y posibilidad de ser ofrecidos y demandados por la NEP es obvia y no amerita efectuar mayores comentarios, pero si quisiéramos destacar los referente a los servicios personales: desde el peluquero hasta los paramédicos y desde la costurera hasta los paramédicos y desde la costurera hasta el técnico, son necesarios en la NEP. Seguramente en sus inicios la NEP necesitará contratar a mucho personal técnico o profesional ubicado en el área económica capitalista, pero la NEP puede ir generando desde sí misma al personal de servicios o crear su propio centro de investigación, capacitación y readiestramiento de sus cuadros.

Por otra parte, siempre en el sentido horizontal de la matriz, esto es, por el lado de la demanda nos aparecen las exportaciones, las cuales incluyen tanto las exportaciones dichas, como las ventas que se efectúen al sector capitalista. Tales exportaciones de la NEP son un factor clave a fin de posibilitar su reproducción en escala ampliada, ya que por una parte se buscaría con las mismas compensar aunque fuese, parcialmente, la succión de excedentes que efectúa el sector capitalista cuando se le compra, pero 
también sería importante a fin de lograr economías se escala y realizar toda la producción excedentaría de la NEP, con lo cual se obtendría el dinero necesario a fin de efectuar las compras al sector capitalista.

Ahora bien, la integración sectorial y ramal que planteamos es evidente que existe de manera extremadamente incompleta, si ocurre es más por accidente que como fruto de un esfuerzo consciente. Así tenemos que al observar los tres sectores claves que hemos establecido para la NEP; producción, financiero y comercio, es evidente que no se cuenta con un sistema financiero propio y basta con dar una ligera mirada a la matriz, para constatar la importancia incuestionable que tiene este sector para el funcionamiento de la NEP. De lo anterior se deduce que si la integración sectorial es una premisa clave para la NEP, la existencia de un Sistema Financiero Popular, se toma una premisa sine qua non de la integración sectorial.

De no contarse con un sistema financiero propio, es obvio que la NEP seguiría adoleciendo de las mismas carencias de financiamiento que presenta la economía popular en la actualidad, lo cual es un grave obstáculo para su desarrollo, pero, también de lograrse algún tipo de financiamiento a las tasas de interés de mercado, o a las onerosas de los agiotistas. Ello significaría una fuerte sangría de excedente para la NEP, lo cual también limitaría su posibilidad de reproducción en escala ampliada. Si algo debe de ser pensado muy en grande por la NEP, esto es: el Sistema Financiero, ya que el mismo no sólo serviría para articular lo que ya existe con las características de la NEP, sino a una parte muy significativa de la economía popular, la cual podría además de ser articulada, irse transformado a fin de adoptar las modalidades de funcionamiento, de distribución del excedente, de almacenamiento y comercialización, de organización y mística, propias de la NEP.

El Sistema Financiero Popular debería de manejar todos los recursos provenientes del exterior y que se destinan a la promoción del desarrollo de los sectores populares, las diferentes líneas de crédito de fomento del Estado, así como absorber a instituciones tales como: el BFA, FSV, FEDECREDITO, FEDECACES, FISS, etc. A su vez podría ser el "banco" de los diferentes ONG, captar ahorros y excedentes de los distintos sectores populares y establecer líneas de crédito para la diez diferentes ramas de la producción, ya sea para la compra de insumo y/o bienes de inversión, así como para el consumo de bienes duraderos, como por ejemplo: la vivienda.

A su vez el "banco" podría prestar asistencia técnica, servicio de almacenamiento y de comercialización exterior, estimular la diversificación de la producción; 
así como capacitación y formación cooperativa; promover el sistema de ayuda mutua en la construcción de viviendas. También podría ser un mecanismo valiosísimo para la captación en el exterior de las remesas de los sectores populares, así como para su orientación hacia actividades productivas al interior de la NEP.

Como se desprende de lo antes ligeramente enumerado, si algo debe de ser pensado e implementado en grande por los sectores populares, esto es: el Sistema Financiero Popular.

Hasta ahora, los diversos fondos o recursos de lo miles y miles de familias que logran algún ahorro o excedente, aunque sea de carácter muy temporal, sólo han servido como un instrumento para la centralización de capital, es hora ya de ponerlos al servicio de los mismos sectores populares.

En cuanto al sector comercio, con carácter popular, presenta una existencia cuantitativamente considerable pero dedicado mayoritariamente a la venta de la producción capitalista nacional o importada, por lo que aquí el problema es mucho más complejo, ya que no se busca su reemplazo sino su integración a la NEP y penetrarlo con la producción popular, lo cual presentaría grandes dificultades en tanto se entre a competir con la producción capitalista.
Cuando hablamos del comercio popular, tenemos en mente desde la vendedora ambulante, el comercio que se da en las calles, en los mercados y las pequeñas tiendas dispersas a lo largo y ancho de todo el país, tanto en el área urbana como rural.

Ciertamente ésta es una actividad muy funcional al capital y ue contribuye de manera significativa a la rotación del mismo, de allí que su integración a la NEP, presenta algunas ventajas pero también grandes dificultades. Por ello, la manera de integrar el comercio popular existente a la NEP, exigirá de estudios especializados o investigaciones particulares.

Ahora bien, en las comunidades que operan a plenitud o de manera significativa bajo lo lógica de la NEP, es claro que lo deseable sería crear cooperativas de compraventa, ello no sólo traería beneficios en cuanto a los precios, sino que sería la forma ideal de privilegiar la venta de la producción popular.

En cuanto a las cooperativas de compra-venta, ello no sólo traería beneficios en cuanto a los precios, sino que sería la forma ideal de privilegiar la venta de la producción popular.

En cuanto a las cooperativas de compra-venta, quisiéramos efectuar algunos comentarios. 
En primer lugar, consideramos que el excedentre o margen del comercio obtenido, debería de tener dos destinos al menos: uno, ampliar la escala de actividad y dos, ser distribuido entre los diferentes miembros de la cooperativa.

En segundo lugar, creemos que al operar con dinero ya sea como medio de circulación (compra al contado) o bien, como medio de pago (compra al crédito) y no, con ausencia del mismo y simplemente asignar una determinada cantidad de bienes, presenta algunas ventajas: posibilita la vinculación con la economía capitalista de manera autónoma, no limita las preferencias del consumidor y a su vez, opera como un mecanismo de regulación del consumo.

Finalmente, las cooperativas de compra-venta, en tanto no son más que parte de la división social del trabajo al interior de la NEP, deberían de cumplir una función de control de calidad, tanto de los bienes demandados al sector capitalista, como de los provenientes $-y$ con especial énfasis- de la producción popular. Adicionalmente, deberían de servir como termómetros del tipo de demanda preferida y enviar sus reportes a los encargados de la producción popular, todo ello, con el fin de evitar la denominada "tiranía del productor".

Otra premisa de suyo muy importante para que la NEP pueda cumplir con su objetivo de equidad es que, la organización de las actividades productivas tenga un carácter cooperativo cuando menos en uno de los cuatro momentos: a) obtención de financiamiento, b) compra y almacenamiento de medios de producción, c) proceso productivo, d) almacenamiento y realización de la producción. Con ello, no sólo se lograría el carácter solidario que deberá prevalecer entre los integrantes de la NEP, sino que iría posibilitando sin mayores presiones el comprender las ventajas que presenta la organización cooperativa. A su vez, implica un elevado grado de flexibilidad y de pragmatismo, que posibilita ir adecuando la teoría a la realidad y no la realidad a la teoría.

Seguramente a los campesinos minifundistas propietarios de su parcela no les entusiasma la idea de integrarse a una cooperativa de producción, ya que para ellos su principal problema no es el cultivo en si mismo, sino la falta de crédito, o la incapacidad de almacenamiento, o la venta de lo producido, etc. Posiblemente, en cualquiera de las otras actividades si encontrarían algún atractivo y a su vez, lograrían superar sus problemas que es precisamente lo que busca la NEP.

De allí que la organización cooperativa haya que verla como una meta o una tendencia, pero no buscar su imposición, porque su mayor beneficio no está en sí misma 
sino en la actitud que se asuma ante la misma.

No se trata pues, de crear o de imponer formas de organización cooperativas porque sí, sino que cuando sus futuros integrantes deseen hacerlo porque están convencidos de su necesidad y/o de sus bondades.
Es más, la noción misma de organización cooperativa debería de repensarse, ya que pudiera contarse con los beneficios de la misma: cooperación, solidaridad, equidad, etc. sin que los miembros de una comunidad estuviesen formalmente organizados en una cooperativa.

\section{Consideraciones finales}

La Nueva Economía Popular en tanto la concebimos como una economía de y para los sectores populares, es obvio que tenga como finalidad la reproducción material y espiritual de los mismos, esto es, satisfacer las necesidades materiales e inmateriales de sus integrantes: niños, adultos y ancianos. En consecuencia, si bien existen algunas premisas básicas o fundamentales para su funcionamiento exitoso, presenta un margen suficiente amplio para dar cabida a las diferentes iniciativas, conforme el grado de maduración del proyecto, a las condiciones particulares en las cuales les toca actuar, etc.

Así por ejemplo, para una determinada comunidad en cierto momento de su desarrollo puede presentarse como muy necesaria la planificación centralizada del proyecto; en otro momento, la centralización lo único que provocaría es una asfixia de las iniciativas. Lo que si no puede despreciarse en cualquiera de los dos casos es el auxilio de la técnica. Para la NEP el conocimiento técnico es vital: el qué, el cómo y el para quién producir, esas viejas interrogantes de la economía, en la NEP deben de encontrar respuestas muy precisas y concretas.

En cuanto a la remuneración del trabajador en la NEP, quisiéramos señalar que ésta es una relación social y que cuando la misma expresa las relaciones entre capitalista y obreros reviste la forma de salario, tal es en rigor la noción de salario, aunque por extensión de la misma categoría se llega a hablar de salario ante cualquier remuneración, sin que exprese en rigor la relación social propia de una economía capitalista.

En la NEP puede presentarse la interrogante: ¿salarización o no salarización? En rigor, la interrogante estaría mal planteada, ya que no se estaría preguntando acerca de si es necesario introducir, conservar o transformar las relaciones de 
producción capitalista, ya que de suyo la NEP, no es una economía capitalista. La pregunta estaría adecuadamente formulada si hiciera referencia a la ¿monetización o no monetización de la economía? La respuesta consideraría dos momentos: uno de reproducción simple o mera subsistencia durante el cual se puede prescindir de la moneda ya que la precariedad de los recursos posibilitaría, incluso una distribución más equitativa de los mismos. Un segundo momento sería el de la reproducción ampliada, en el cual la monetización de la economía se presenta como una necesidad y el mercado entra a jugar un rol hasta ahora no prescindible. Dentro de esa monetización caben las remuneraciones a los trabajadores, las cuales pueden, sin embargo, seguir preservando una parte no monetizada, cuales serían los servicios de educación, salud, esparcimiento, etc que deberían ser recibidos por todos los miembros de la comunidad, por el simple hecho de ser miembros de la misma, aunque su costo sea pagado por los trabajadores productivos. ${ }^{4}$

Ahora bien, el trabajador en la NEP no sólo participa en la distribución vía remuneración y servicios sociales, sino que en la medida que sea integrante de una determinada forma de organización cooperativa también podría tener acceso a parte del excedente distribuible generado o captado en la cooperativa, el cual podría funcionar como un ahorro forzoso durante un determinado período, al menos.

La modernización de las remuneraciones al trabajador presenta las ventajas siguientes: primero, se logra con ello incentivar el esfuerzo individual, lo cual beneficia al trabajador y su familia ya que contara con mayores ingresos disponibles; segundo, se beneficia toda la comunidad en tanto que los mejores esfuerzos individuales se traducen en un mayor producto disponible para la misma; tercero, el trabajador en tanto que consumidor cuenta con libertad de elegir y en esa medida de satisfacer sus preferencias individuales y cuarto, la comunidad ahorra en términos de trabajo social al no tener que ocuparse del aprovisionamiento, distribución y control de las asignaciones en términos físicos, ya que resulta mucho más sencillo el manejo en términos de unidades de valor, esto es, con la moneda.

Los riesgos que implica tal forma monetizada de las remuneraciones es que los trabajadores se abastezcan mayoritariamente de bienes producidos en el sector capitalista, con lo cual se estaría desfavoreciendo la integración sectorial de la NEP. Pero, ello, a su vez, considerado positivamente puede constituirse en un estímulo para que la NEP mejore la productividad del trabajo y la calidad de lo producido, a fin de ofertar bienes de igual o mejor calidad a menores precios. 
Finalmente quisiéramos destacar que la Nueva Economía Popular, se presenta ya en forma embrionaria en algunas comunidades del país, de allí que deseamos hacer un llamado a las instituciones y organizaciones no gubernamentales a fin de continuar brindado su respaldo moral y su apoyo material a las mismas, así como al gobierno de la república para que lejos de entorpecer su desarrollo, fomente el mismo en el período de reconstruc-

Notas

1. Véase: "Reacumulación primaria del capital en El Salvador”. Revista ECA, sept. 1991.

2. Sobre este tema, consúltense nuestros trabajos: "Necesidad teórica de la categoría subsunción indirecta del trabajo en el capital", "El comercio no capitalista y su carácter indirectamente subsumido en el capital" y "La producción agrícola no capitalista y su relación con el capital”, publicados en la Revista Realidad Económico-Social, enero-febrero, ción nacional canalizado recursos materiales y humanos hacia estos sectores, pero sin alterar su lógica de organización y funcionamiento, ya que ésta ha evidenciado grandes potencialidades para resolver los problemas de los sectores populares, de allí que merece una oportunidad a fin de desarrollarse y consolidarse como una estrategia alternativa de y para las mayorías populares, lo cual, obviamente, corresponde al interés nacional.
1988, julio-agosto, 1988 y enerofebrero, 1989, respectivamente.

3. Para un cuestionamiento de tal postura véase: "El otro sendero: los presupuestos teóricos de Hernando de Soto" de Carlos G. Ramos en Revista Realidad Económico-Social. Enero-abril de 1991.

4. En el contexto de la NEP, el trabajo productivo es todo aquel que genere valor y/o valor de uso. 